\title{
Repensando a Avaliação no Curso de Pedagogia: o portfólio como uma prática possível
}

\author{
BENIGNA MARIA DE FREITAS VILLAS BOAS \\ Doutora em Educação pela UNICAMP. Pós-doutorado em Educação no Instituto \\ de Educação da Universidade de Londres. Professora da Faculdade de Educação \\ da Universidade de Brasília \\ mbboas@terra.com.br
}

\begin{abstract}
Resumo
O texto apresenta resultados parciais de uma pesquisa que está sendo conduzida no Curso de Pedagogia para professores em exercício no início de escolarização (PIE), oferecido pela Faculdade de Educação da Universidade de Brasília (UnB), em convênio com a Secretaria de Estado de Educação do Distrito Federal. Esse curso atende, durante o ano de 2003, a 2000 professores que têm apenas o Curso de Magistério, em nível médio. Como todos os alunos do curso são também professores em exercício, optou-se pela adoção do portfólio para que eles vivenciem uma prática avaliativa que possa romper com a avaliação classificatória, seletiva e excludente e possam praticá-la com seus próprios alunos. Discutem-se as percepções dos mediadores sobre as reações dos professores-alunos quanto ao uso do portfólio, coletadas por meio da aplicação de um questionário. Apresentam-se, ao final do texto, sinalizações ainda provisórias e conclui-se que, para que o portfólio cumpra o objetivo de promover a aprendizagem do professor-aluno do PIE por meio da construção, reflexão, criatividade, parceria, auto-avaliação e autonomia, deve inserir-se no trabalho pedagógico que considere estes mesmos princípios.

Palavras-chave: avaliação, portfólio, trabalho pedagógico, formação de professores.
\end{abstract}

\section{Resumen}

Este escrito presenta resultados parciales de una investigación que esta siendo realizada en el curso de Pedagogía para profesores siendo capacitados y en la activa (PIE), ofrecido por la Facultad de Educación de la Universidad de Brasilia (UnB), dentro de un convenio con la Secretaria de Educación del Distrito Federal. El curso atiende, durante el año 2003, a 2000 profesores que tienen solamente el curso de Profesor, de nivel medio. Como todos los alumnos del curso son también profesores escogimos el Portafolio para que ellos tengan la experiencia de una practica de evaluación que pueda romper con la evaluación clasificatoria, selectiva y excluyente y puedan practicarla con sus propios alumnos. A través de la aplicación de un cuestionario se discuten las percepciones de los mediadores sobre las reacciones de los profesores - alumnos cuanto al uso del portafolio. Al final del escrito se presentan de forma incipiente algunas indicaciones y se concluye que para que portafolio cumpla el objetivo de aumentar la capacidad de aprendizaje del profesor alumno del PIE a través de la construcción, reflexión, creación, colaboración, auto evaluación y autonomía, debe estar inserido en el trabajo pedagógico que atienda estos mismos principios.

Palabras-clave: evaluación, portafolio, trabajo pedagógico, formación de profesores. 


\begin{abstract}
The text presents partial findings of a research conducted in the Undergraduate Program in Education for public elementary school teachers. This course is co-sponsored by the College of Education of the University of Brasilia and the Secretary of Education of the Federal District. In 2003 two thousand student-teachers are attending the program. Considering that all students are also teachers, the course coordination decided to adopt the portfolio so that they can experience an assessment practice different from the one that classifies, selects and excludes students. It is also important that they be assessed by a procedure they can use with their own students. The text discusses the mediators' perceptions about studentteachers'reactions in relation to the portfolio assessment, collected by means of a questionnaire. In conclusion, it is pointed out that in order for the portfolio to meet its objective of promoting learning through the principles of construction, reflection, creativity, partnership, self-assessment, and autonomy, it has to be part of the pedagogic work that takes into account these principles.
\end{abstract}

Key words: assessment, portfolio, pedagogic work, teacher education. 


\section{SITUANDO O TEMA}

Este texto apresenta resultados parciais de uma pesquisa que está sendo conduzida no Curso de Pedagogia para professores em exercício no início de escolarização (PIE), oferecido pela Faculdade de Educação da Universidade de Brasília (UnB) em convênio com a Secretaria de Estado de Educação do Distrito Federal. Esse curso atende, durante o ano de 2003, a 2000 professores que têm apenas o Curso de Magistério, em nível médio.

Principalmente o fato de os alunos do PIE serem professores em exercício provocou a necessidade da adoção de processo avaliativo que levasse em conta essa característica, de modo que eles não apenas "estudassem sobre a avaliação", como costumeiramente se faz, mas praticassem a avaliação que busque superar a sua função tradicional de dar nota e aprovar e reprovar o aluno, mantendo, assim, a classificação, a seleção e a exclusão. Decidiu-se, então, pela utilização do portfólio, de modo que o curso trabalhasse simultaneamente a teoria e a prática da avaliação.

Qualquer curso de formação de professores enfrenta o seguinte desafio: estudar, pesquisar e analisar a avaliação integrada ao trabalho pedagógico voltado para a formação do cidadão independente e crítico, mas, ao mesmo tempo, praticá-la de forma convencional, isto é, para aprovar ou reprovar os alunos, adotando procedimentos padronizados e descontextualizados? Ou vivenciar e construir, juntamente com os alunos, práticas avaliativas que promovam a sua aprendizagem e os ajudem a selecionar as que poderão utilizar quando estiverem atuando em escolas? No caso do PIE, esse desafio é ainda maior porque todos os cursistas são professores em exercício. Como resposta a esse desafio, adota-se como procedimento de avaliação o portfólio, que vem sendo construído por todos os professores-alunos, para que cada um possa acompanhar o andamento das suas atividades. De modo geral, o que acontece em cursos de nível superior é o professor aplicar e corrigir provas, registrar os resultados e devolvê-las aos alunos. Além disso, costumam ser solicitadas atividades, como produções de textos, elaboração e desenvolvimento de projetos, trabalhos de campo e outras, entregues ao professor para avaliação. Este, após fazer suas observações, devolve ao aluno seus trabalhos, conservando apenas números e/ou palavras sobre o que foi realizado. Ao final do período letivo, ele recorre aos seus registros para emitir o julgamento final, em forma de nota ou menção. Contudo, não tem mais em mãos os trabalhos dos alunos, para que possa analisar a sua trajetória de aprendizagem. 
O PIE decidiu enfrentar o desafio de analisar teoricamente a avaliação e, ao mesmo tempo, avaliar as produções do professor-aluno por meio de um processo que corresponda à teoria estudada. Como a avaliação por meio do portfólio constitui uma prática recente entre nós, está sendo acompanhada e investigada pelo grupo de pesquisa Avaliação e Organização do Trabalho Pedagógico ${ }^{1}$, que desenvolve, no momento, um grande projeto de pesquisa sobre Práticas Avaliativas Inovadoras, no qual se insere a pesquisa cujos resultados parciais são aqui descritos. Um dos objetivos desta investigação é analisar as percepções dos mediadores e dos professores-alunos sobre o uso do portfólio como procedimento de avaliação. Neste texto são apresentadas e analisadas brevemente as percepções de 36 mediadores (o número total é 44), obtidas por meio da aplicação de um questionário.

\section{COMO SE ORGANIZA O TRABALHO PEDAGÓGICO DO PIE}

O Curso de Pedagogia para professores em exercício no início de escolarização (PIE) é um curso com duração de 3 anos, oferecido com características de semi-presencialidade, com carga-horária de 3.210 horas ( $40 \%$ presenciais e $60 \%$ não-presenciais), destinado a professores em exercício na Educação Infantil ou no início de escolarização do Ensino Fundamental da Rede Pública de Ensino do Distrito Federal, portadores de habilitação para o Magistério, em nível médio.

A carga horária não-presencial $(60 \%)$ destina-se ao trabalho com recursos de tecnologia multimídia, especialmente textos "mediáticos" impressos, vídeos e interação pela internet. Considera-se nessa carga o trabalho de regência efetiva do professor-aluno.

A carga horária presencial (40\%) destina-se ao desenvolvimento de projetos individuais e coletivos, seminários, conferências, encontros de socialização de experiência, aulas expositivas, atividades nos laboratórios de informática etc.

O curso teve início em 2001, com um grupo de mil professoresalunos. Em 2002 outro grupo de mil passou a freqüentá-lo. As negociações da UnB com a Secretaria de Estado de Educação do DF previam, em 2001, que o universo de professores em exercício, com apenas o Curso de Magistério, num total de 5000, faria o curso na UnB. Em 2002, após uma greve de professores da UnB, por interesse da Secretaria de Estado de

${ }^{1}$ Grupo de pesquisa cadastrado pelo CNPq e certificado pela UnB, que tem como líder a professora Benigna Maria de Freitas Villas Boas. 
Educação, decidiu-se que a UnB atenderia apenas 2000 professores. O outro grupo de 3000 passou a ser atendido por uma instituição privada.

A programação do curso é desenvolvida por coordenadores, tutores e mediadores. Os coordenadores são professores da Secretaria de Estado de Educação do DF, colocados à disposição da Faculdade de Educação da UnB, aos quais foi oferecido um curso de especialização, nos anos de 2001 e 2002, como parte do Programa do PIE.

Os tutores são os professores que, além de serem os autores dos módulos de trabalho, encontram-se sistematicamente com os mediadores e, em alguns momentos, com os professores-alunos, para análise mais aprofundada dos temas.

Os mediadores, em número de 44, são professores da Secretaria de Estado de Educação do DF, também colocados à disposição da Faculdade de Educação da UnB, que também participaram do curso de especialização. Observa-se, então, que um dos pontos fortes desse programa foi a formação dos coordenadores e dos mediadores para a sua atuação. O curso de especialização teve a duração de três semestres e suas atividades foram desenvolvidas pelos professores tutores e autores dos módulos de trabalho. Enquanto esse grupo se formava, concomitantemente já exercia as atividades de mediação. A teoria e a prática compreendiam as atividades do curso de especialização e as realizadas com os professores-alunos. Esse fato tornou o PIE uma iniciativa singular e inovadora.

Os mediadores encontram-se com os professores-alunos nas escolas em que estes últimos trabalham, em espaços da UnB e nos Centros Regionais Informatizados para a Educação (CRIE), que são laboratórios de informática em que todos têm acesso ao computador como ferramenta que proporciona, em tempo real, informações gerais e específicas sobre temas, além de promover a interatividade e troca de experiências. O professoraluno tem a possibilidade de ampliar seus conhecimentos sobre a forma de desenvolver o trabalho pedagógico acessando recursos multimídias, consultando colegas, especialistas, obtendo respostas sobre métodos, materiais, estratégias de desenvolvimento de temas etc. Os encontros nos laboratórios constituem momentos privilegiados de familiarização com o computador e com o acesso à Internet, possibilitando ao professor-aluno viver novas experiências.

\section{O PORTFÓLIO E A FORMAÇÃO DE PROFESSORES}

A sociedade cada vez mais exige a formação de professores altamente preparados para desenvolver o trabalho pedagógico que cumpra 
a função primeira da educação escolar: garantir que todos os alunos aprendam o indispensável para o exercício da cidadania plena. Veiga (2002, p. 83) propõe que a formação do professor se desenvolva na perspectiva de uma educação crítica e emancipadora que considere, dentre outros aspectos: a construção e domínio dos saberes da docência identificados por Tardif et al (1991) como os saberes disciplinares e curriculares, saber da formação pedagógica, saber da experiência profissional e saberes da cultura e do mundo vivido na prática social; a unicidade entre teoria e prática, perpassando todo o processo de formação; o trabalho como princípio educativo e a pesquisa como meio de produção de conhecimentos e intervenção na prática social e especificamente na prática pedagógica; a ação coletiva que integre não apenas todo o pessoal que atua na escola mas, também, todos os processos que contribuem para a melhoria do trabalho pedagógico; a autonomia "como valor profissional do pensamento e da ação, aspirando a um maior controle sobre o trabalho pedagógico".

De modo particular, três destes aspectos justificam a adoção do portfólio como procedimento de avaliação em cursos de formação de professores: a construção e domínio dos saberes da docência, a unicidade entre teoria e prática e a autonomia.

O portfólio tem sido considerado no PIE um dos saberes a serem incorporados pelos professores-alunos e pelos mediadores, em articulação com a teoria e prática. Considera-se o portfólio não apenas como procedimento de avaliação, mas como o eixo organizador do trabalho pedagógico, devido à importância que ele passa a ter durante todo o processo.

A preparação para a avaliação tem sido um saber marginalizado na formação de professores. O uso do portfólio pode ser uma forma de colocála em debate justamente em um dos espaços a ela destinados, o da formação de professores. Isso requer mudança de concepção de avaliação: o professor deixa de ser o "examinador" e o aluno o "examinado". Atua-se em parceria, sem com isso perder-se o rigor e a seriedade que a atividade impõe. Pelo contrário, a avaliação torna-se mais exigente porque torna-se, também, transparente. Não significa também retirar a responsabilidade do professor para transferi-la ao aluno, mas possibilitar a este vivenciar o processo que ele possa desenvolver com seus alunos, de modo a superar os problemas que tanto temos combatido. Contudo, alerta Murphy (1997, p. 87), isso somente poderá ocorrer em ambiente que propicie o desenvolvimento profissional do professor, incluída a sua autonomia intelectual e condições adequadas de trabalho.

Tardif $(2002$, p. 23) expressa sua vontade de "encontrar, nos cursos de formação de professores, uma nova articulação e um novo equilíbrio 120 Estudos em Avaliação Educacional, n. 27, jan-jun/2003 
entre os conhecimentos produzidos pelas universidades 'a respeito' do ensino e os saberes desenvolvidos pelos professores 'em' sua práticas cotidianas". Até agora, afirma o autor, a formação para o magistério tem sido feita por meio de conhecimentos disciplinares geralmente produzidos em uma "redoma de vidro", e, posteriormente, aplicados na prática em forma de estágios e outras atividades semelhantes. O autor considera que os professores são atores competentes, sujeitos ativos e que sua prática não é apenas "um espaço de aplicação de saberes provenientes da teoria, mas também um espaço de produção de saberes específicos oriundos dessa mesma prática" (op. cit., p. 234). Isto significa que ele desenvolve e produz teoria da sua própria ação. Contudo, tal concepção da relação teoria e prática ainda é pouco vivenciada nos cursos de formação de professores. No caso do PIE, em que o aluno já é professor, o uso do portfólio possibilita o desenvolvimento da construção teórica e prática da avaliação: o trabalho do professor-aluno durante o curso é avaliado por meio do processo que ele poderá desenvolver com seus próprios alunos com o intuito de superação da avaliação classificatória e excludente. Parte das produções do seu portfólio constitui-se de reflexões sobre as possibilidades do seu uso com seus alunos.

A opção pelo uso do portfólio no PIE baseou-se, também, na crença de que o professor constrói a sua autonomia enquanto se forma. Nada melhor do que a avaliação para contribuir para esse processo. Pode-se afirmar, com a ajuda de Contreras (2002, p. 204), que a "autonomia deve ser entendida como a independência intelectual que se justifica pela idéia da emancipação pessoal da autoridade e do controle repressivo, da superação das dependências ideológicas ao questionar criticamente nossa concepção de ensino na sociedade". Essa posição possibilita aos professores desempenharem o seu papel de distanciamento crítico necessário ao trabalho pedagógico que tem por objetivo a formação do cidadão para ter inserção social crítica.

Assim concebido, o portfólio possibilita avaliar as capacidades de pensamento crítico, de articular e solucionar problemas complexos, de trabalhar colaborativamente, de conduzir pesquisa, de desenvolver projetos e de o aluno formular os seus próprios objetivos para a aprendizagem (Murphy, 1997, p. 72). O professor e o próprio aluno avaliam todas as atividades executadas durante um largo período de trabalho, levando em conta toda a trajetória percorrida. Não é uma avaliação classificatória nem punitiva. Analisa-se o progresso do aluno. Valorizam-se todas as suas produções: analisam-se as últimas comparando-as com as primeiras, de modo a se perceber o avanço obtido. Isso requer que a construção do portfólio se baseie em propósitos de cuja formulação o aluno participe, para 
que se desenvolva o sentido de "pertencimento". Desse modo, o portfólio extrapola a sua função avaliativa e passa a ser o eixo organizador do trabalho pedagógico, porque este assume outro significado: o aluno é coresponsável por sua organização. Murphy (1997, p. 73) considera que os portfólios "oferecem uma das poucas oportunidades escolares em que os alunos podem exercer seu julgamento, iniciativa e autoridade". Em cursos de formação de professores isso torna-se fundamental porque a tendência é eles trabalharem com seus alunos da forma como foram tratados por seus professores.

Contudo, ensina Murphy (op. cit., p. 74), para que os portfólios atendam às características acima, não podem ser altamente prescritivos porque podem restringir as oportunidades de professores e alunos demonstrarem iniciativas individuais. $\mathrm{O}$ trabalho com o portfólio requer a criação de situações dasafiadoras e de ambiente de aprendizagem que fortaleça a autonomia do aluno. Percebe-se, então, que o portfólio não é um simples procedimento de avaliação: um novo entendimento de trabalho pedagógico e de avaliação é necessário.

Klenowski (2000, p. 221) relata estudos conduzidos por alguns pesquisadores em cursos de formação de professores, sobre o uso do portfólio: Bull e Richert concluíram que o portfólio ajudou os professores a se tornarem mais reflexivos, principalmente porque, enquanto selecionavam os materiais a serem incluídos, eles pensavam sobre as atividades que desenvolviam com seus alunos e quão bem eles as realizavam, assim como analisavam se os materiais usados correspondiam aos objetivos de trabalho; Vavrus \& Collins observaram que, enquanto construíam seus portfólios, os professores analisavam se suas práticas pedagógicas correspondiam às necessidades de seus alunos. Quando o conteúdo do portfólio era acompanhado por descrições reflexivas, comentam os mesmos autores, "a complexidade do ensino parecia ter sido captada" (apud Klenowski, 2000, p. 222). Combinações de diferentes tipos de documentos, como exemplares de produções dos alunos, fitas cassete e de vídeo mostrando as práticas pedagógicas, planos de trabalho e outros podem auxiliar a traçar toda a trajetória do trabalho, desde o planejamento até a avaliação, complementam os pesquisadores.

Klenowski (op. cit., p. 222) afirma que a literatura demonstra que a avaliação por meio do portfólio em cursos de formação de professores pode fortalecer a prática reflexiva.

No PIE o trabalho com o portfólio tem se apoiado em seis princípios básicos (Villas Boas, 2001, p. 207): a construção pelo próprio aluno, possibilitando-lhe fazer escolhas e tomar decisões; a reflexão sobre as suas produções; a criatividade, porque o aluno escolhe a maneira de organizar o 
portfólio e busca formas diferentes de aprender; a auto-avaliação pelo aluno, porque ele está permanentemente avaliando o seu progresso; a parceria professor-aluno e entre alunos, eliminando-se ações e atitudes verticalizadas e centralizadoras; a autonomia do aluno frente ao trabalho. Ele percebe que pode trabalhar de forma independente e que não precisa ficar sempre aguardando orientação do professor.

Klenowski (2000, p. 232) aponta seis princípios norteadores do trabalho com o portfólio em cursos de formação de professores: a perspectiva de aprendizagem independente é encorajada; a avaliação é praticada como um processo; o aluno documenta e analisa todas as atividades realizadas; a auto-avaliação é parte integrante do processo avaliativo; o aluno coleta e seleciona informações, ao mesmo tempo em que reflete sobre o trabalho desenvolvido; o professor é o orientador de todo o processo.

\section{METODOLOGIA}

Como a pesquisa está em desenvolvimento, para efeito deste artigo foi considerada somente a parte relacionada à percepção dos mediadores quanto ao uso do portfólio como procedimento de avaliação no Curso de Pedagogia para professores em exercício no início de escolarização - PIE. Nenhum dos mediadores havia trabalhado anteriormente com o portfólio e quase a totalidade dos professores-alunos não o conhecia. Portanto, tornouse necessária a condução de uma investigação que respondesse às seguintes questões: como os mediadores se sentem ao participar de uma avaliação por meio de portfólio? Quais são suas percepções sobre as reações dos professores-alunos quanto ao uso do portfólio?

Os dados aqui relatados foram coletados por meio de um questionário aplicado a 36 dos 44 mediadores, no mesmo dia e horário e, imediatamente, recolhido.

Apresentam-se, a seguir, as percepções coletadas.

\section{OS MEDIADORES APRESENTAM AS REAÇÕES DOS PROFESSORES-ALUNOS AO USO DO PORTFÓLIO: “RELAÇÃO DE AMOR E ÓDIO"}

As palavras/expressões mais usadas pelos mediadores para descreverem as reações dos professores-alunos são relacionadas à resistência e a dificuldades encontradas: medo, repulsa, dúvidas, 
insegurança, estresse, sofrimento, questionamento, angústia, preocupação, ansiedade, estranhamento, incompreensão, fardo a mais, "sentem-se assustados, confusos, perdidos, apavorados", rejeição, apreensão, aversão. As palavras mais freqüentes foram medo e insegurança. O portfólio chegou a ser rotulado de o "bicho papão" do curso.

Segundo uma mediadora, a causa do "sofrimento" está no fato de os professores-alunos não terem segurança quanto ao "certo" ou "errado" das suas produções.

Vários depoimentos esclarecem que, passado o primeiro momento de "estranhamento", vem o segundo, traduzido pela sensação de "descoberta de algo novo" e de prazer mas que, mesmo assim, há um grupo que mantém a sua discordância quanto ao uso do portfólio e, conseqüentemente, sua resistência. Segundo os depoimentos dos mediadores, parece que a maioria dos professores-alunos aprova o uso do portfólio.

Além das reações negativas, que têm predominado no início das atividades, "após orientações e textos de apoio, os professores-alunos começam a vislumbrar o caminho a trilhar" e a apresentar as seguintes atitudes positivas quanto ao novo processo avaliativo: curiosidade; admiração; alegria; paixão; orgulho pelo que têm conseguido produzir; aceitação; tranqüilidade; "sentem-se felizes em produzir, em divulgar seus trabalhos (momento de autoria)"; "confiança na mediadora"; interesse; criatividade; "encaram o desafio e se comprometem com ele"; "busca pela fundamentação para terem segurança"; entusiasmo; prazer "de construir e acompanhar a sua avaliação" e ao "perceber a riqueza que é o portfólio"; "abertura para entender e acolher esse processo avaliativo".

Com relação às atitudes positivas, a palavra mais usada pelos mediadores é "tranqüilidade". Um dos relatos aponta que após o medo inicial da construção, "a partir do momento em que os trabalhos vão sendo apreciados pelo mediador, paira um ar de tranqüilidade por parte dos professores-alunos".

Observou-se que uma das palavras mais usadas pelos mediadores, em suas respostas aos itens do questionário, é "construção", um dos princípios-chave do trabalho com o portfólio, já apresentados (Villas Boas, 2001, p. 207).

As informações fornecidas pelos mediadores possibilitam a formulação das considerações que se seguem. Em primeiro lugar, cabe destacar que o portfólio constitui um processo avaliativo completamente diferente daquele vivenciado até o momento pelos professores-alunos e também pelos mediadores. Os princípios nos quais se apóia não costumam fazer parte do trabalho pedagógico das escolas e dos cursos de formação 
dos profissionais da educação. A avaliação e todo o trabalho pedagógico no qual ela se insere têm sido prescritos pelos professores e pelas autoridades educacionais. De modo geral, o trabalho pedagógico visa à aquisição da aprendizagem do aluno mas não se prevê, ao mesmo tempo, o desenvolvimento do professor e da escola. A organização do trabalho pedagógico baseado na concepção de que professores e alunos executem o que outros pensaram continua fortemente presente nas escolas de todos os níveis. Portanto, a proposta de utilização do portfólio é inovadora porque procura eliminar o autoritarismo ainda presente na avaliação e na organização do trabalho pedagógico. Porém, mudança provoca medo, insegurança, angústia, resistência e até mesmo sofrimento, como foi apontado. Segundo uma mediadora, alguns professores-alunos

comentam que a prova é mais legal para essa modalidade de ensino. No entanto, ao começarem a produzir o memorial descritivo, já começam a tomar gosto e parece que tudo começa a fluir, então, elaboram trabalhos maravilhosos. Uns, mesmo fazendo bons trabalhos, ainda resistem.

Em segundo lugar, é preciso entender que a relação de "amor e ódio", expressão usada por uma mediadora, pode ter várias interpretações. Uma delas pode estar relacionada à consideração anterior. Além disso, uma mediadora oferece a seguinte pista para a compreensão dessa questão: "tenho observado que os professores que gostam (de construir o portfólio), em geral, foram bem avaliados pelo seu trabalho e os que não gostam tiveram problemas quanto à avaliação". Portanto, pode-se entender que o gostar ou não de construí-lo relaciona-se com a forma de organização e desenvolvimento do trabalho, o que coloca grande responsabilidade na atuação do mediador.

Em terceiro lugar, a resistência ao uso do portfólio não é um ato isolado. Deve ser compreendida levando-se em conta a formação do professor e o ritual pedagógico geralmente presente nas escolas onde atuam. No caso do PIE, em que os cursistas são professores em exercício, essa dualidade está presente. Só que eles têm uma formação para o magistério (em nível médio) com grandes chances de ter sido feita nos moldes tradicionais, parecem desenvolver trabalho pedagógico dessa mesma forma, nas escolas onde trabalham, e estão vivenciando no PIE uma formação que procura superar essas dificuldades já acumuladas.

O trabalho com o portfólio tem sido uma experiência nova para todo o grupo de mediadores e professores-alunos. Segundo um dos mediadores, para os professores-alunos a reação tem sido "de muita curiosidade e insegurança por ser sua primeira experiência neste tipo de avaliação". 
Segundo a percepção dos mediadores, os principais aspectos facilitadores da construção do portfólio pelos professores-alunos são os seguintes: o diálogo, a troca de experiência entre colegas e mediadores; a constante reflexão sobre o trabalho e os saberes adquiridos; o prazer de ter, num mesmo instrumento, a visão total do que ele (professor-aluno) vem produzindo e de como vem crescendo; a proposta de construir o portfólio a cada dia e sem atropelos; a liberdade de poder escrever usando diferentes linguagens; o contato com livros, artigos e documentos que complementam os módulos; o fato de poder escolher a sua formatação e o que vai ser inserido como material complementar; a liberdade de expressão, a exposição dos trabalhos realizados e o estabelecimento do vínculo teoria (PIE) e prática pedagógica; a possibilidade do trabalho transversal com temas; a não-linearidade temporal da sua construção; a processualidade (o trabalho sendo analisado durante o processo); a autonomia; o trabalho de mediação; acompanhamento dos próprios avanços; a experiência vivida nos semestres anteriores.

\section{“A GENTE FAZ O PORTFÓlIO PENSANDO EM QUEM VAI AVALIAR"}

Segundo a percepção dos mediadores, a falta de tempo para a construção do portfólio tem sido a maior dificuldade encontrada pelos professores-alunos (recebeu 11 referências), seguida da resistência para escrever porque "os professores de modo geral não gostam de escrever". Assim, "as primeiras reflexões são muito superficiais, com a continuação é que vão superando essa barreira". Concorrem para isso as dificuldades de "decidir autonomamente sobre evidências de aprendizagem que farão parte do portfólio", de "produzir (em oposição ao reproduzir o que foi vivenciado em toda a sua vida escolar)" e de "escrever as próprias idéias". Outro entrave diz respeito ao fato de os professores-alunos estarem "presos às amarras da avaliação tradicional que mensura" e a "falta de costume de avaliar suas próprias produções" e de "escrever e registrar". Afirma uma mediadora: "a avaliação formativa/processual é ainda um desafio muito grande pois não passamos por ela e agora que temos a oportunidade nos sentimos cheios de dificuldades". Foram indicadas outras dificuldades: de aceitá-lo como instrumento de avaliação; a preocupação em ter um "modelo" pré-estabelecido; a resistência por não haver uma receita; falta de leitura; incompreensão do que pode e do que não pode ser incluído; entendimentos diversos sobre o portfólio por parte dos mediadores; resistência ao novo; muito trabalhoso "já que a reflexão é parte de todas as 
atividades propostas"; sobrecarga de trabalho; falta de entendimento por parte dos próprios mediadores; apresentação de forma padronizada; avaliação subjetiva do mediador; falta de compreensão dos propósitos e dos descritores de avaliação; visão diferenciada do portfólio; nãocompreensão do princípio da reflexão; a concepção ainda arraigada da avaliação tradicional; falta de prática reflexiva para redigir, escrever, analisar, auto-avaliar; "dificuldade em produzir textos por não estudarem (formalmente) há muitos anos"; o fato de os mediadores não terem vivenciado a construção de um portfólio; desconhecimento do que seja um portfólio na educação.

Em síntese, parece que a avaliação por meio do portfólio tem trazido insegurança gerada pela compreensão já incorporada de que a avaliação tradicional (realizada somente pelo professor, com o objetivo de dar nota e de aprovar e reprovar) é a que é séria. Além disso, parece permanecer a resistência a um procedimento que exige mais trabalho por parte do aluno porque ele tem de construir, refletir sobre o que faz, analisar, buscar informações complementares, acompanhar e avaliar o seu progresso, registrar suas produções, com vistas a conquistar sua autonomia intelectual. Em um primeiro momento, esse processo assusta porque é trabalhoso e de grande responsabilidade. Para o aluno é tão natural aceitar pacificamente a avaliação que lhe é imposta que, ao ter a chance de ser o sujeito da sua aprendizagem, [...] "faz o portfólio pensando em quem vai avaliar" e não no seu progresso. A superação da avaliação classificatória, seletiva e excludente continua sendo, então, um desafio.

\section{DENTRE FACILIDADES E DIFICULDADES, "UMA DIFICULDADE IMENSA DE NÃO COMPARAR AS PESSOAS E SUAS PRODUÇÕES"}

Além de o trabalho com o portfólio ser novo para os mediadores e os professores-alunos, a fundamentação teórica sobre esse tema está sendo construída por eles. Talvez por esse motivo tenham sido apresentados mais aspectos dificultadores do que facilitadores.

Os seguintes aspectos resumem as dificuldades do grupo de mediadores em avaliar o desempenho do professor-aluno por meio do portfólio: ser um processo novo para ele, que valoriza o progresso individual e grupal, não permitindo que se comparem pessoas e suas produções; e, na situação atual, a exigência de atribuição de menções.

Ao serem indagados sobre como analisam o seu trabalho de coordenação da construção do portfólio pelos professores-alunos, os mediadores afirmaram que ainda convivem com insegurança e incertezas: 
"faltam habilidades para fazer uma avaliação dessa amplitude"; "extremamente difícil pois acho que temos uma tendência a comparar as pessoas e suas posições"; "difícil, porém, interessante e prazeroso"; "em construção, muitas aprendizagens e muitas dúvidas"; "tento ajudar, provocar e desafiar as idéias e/ou projetos que eles já trazem"; [...] "parece que ninguém entende de Portfólio e fica aquela guerra de concepções"; "tenho procurado aplicar os princípios que norteiam o portfólio, sobretudo o da reflexão e o da parceria"; "faço a apreciação do portfólio em conjunto com o professor-aluno e estabelecendo os critérios com a turma"; "atendo individualmente os professores-alunos dando sugestões. Penso ser esse o meu papel"; [...] "sempre que há alguma insegurança ou equívoco relacionados com a construção do portfólio, retomo com o grupo"; "estou vivenciando um processo novo e tudo o que é novidade iniciamos de maneira tímida, mas estamos caminhando muito bem"; "faço anotações das considerações prévias da construção e oportunizo momentos de socialização dos grupos com suas idéias e construções prévias"; "fico no dilema entre ser autoritária (nortear, definir), estabelecendo o que desejo que seja registrado, e entre ser mais flexível, deixando a cargo dele que faça tal registro".

Os mediadores também apontaram os aspectos que têm dificultado a sua atuação: discussões/orientações ainda insuficientes; a grande quantidade de textos a ser apreciada e a variedade de temas desenvolvidos durante o semestre; atendimento a número grande de professores-alunos; convivência com um processo inovador de avaliação e a necessidade de se atribuírem menções; enfrentar a resistência de alguns professores-alunos; espaço ainda insuficiente de discussão entre os mediadores; a própria formação; o fato de nunca ter construído um portfólio foi a dificuldade inicial; as comparações feitas pelos próprios cursistas quanto à diferença de exigência dos mediadores; a não-construção do portfólio pelos mediadores no curso de especialização; enfrentar a subjetividade da avaliação; lidar com a autonomia do professor-aluno para construir o portfólio: orientar, determinar, sugerir etc.; momentos insuficientes para acompanhamento do processo; a resistência de alguns professores-alunos; tempo reduzido para dialogar oralmente com cada cursista.

Ao lado da insegurança em coordenar um processo avaliativo novo para todo o grupo, apresentaram-se, também, manifestações positivas, como as seguintes:

O portfólio é um instrumento riquíssimo que garante a beleza da construção própria, individual, personalizada. Costumo dizer aos cursistas que é um momento de duplo prazer no processo educacional: você como autor/produtor de sua vivência 
e ao mesmo tempo leitor de sua obra, de sua prática, de sua atuação pedagógica. Autor e leitor de si mesmo!

Desde o início, sem nunca ter passado por essa experiência com o portfólio, eu senti muita segurança em avaliar os cursistas porque as produções e atividades, ou seja, o seu desenvolvimento estava demonstrado e organizado para todos que quisessem ver: a mediadora, o cursista, os colegas, a família, a coordenação do PIE.

No início era tudo muito novo, o medo de errar era enorme e o que foi garantindo uma maior segurança/autonomia foi a discussão coletiva, o estudo e o processo cotidiano de troca/socialização dos trabalhos, a orientação inicial foi muito sofrida. Hoje é tudo mais tranqüilo, muitos desafios ainda se fazem presentes, mas um pouco de conhecimento, de experiência que temos já nos permite avanços significativos e de qualidade.

Outras atitudes e manifestações de segurança e de prazer com o trabalho foram apontadas: "feliz em ver muita beleza, muita reflexão e de presenciar muita transformação pedagógica"; "segura; todo o processo está lá descrito. Dá mais trabalho, mas o resultado tem muito mais significado e espelha melhor a aprendizagem de cada aluno".

Um dos mediadores revelou ter alcançado segurança após o trabalho com o primeiro grupo de professores-alunos:

Na primeira turma foi um trabalho superficial, apesar de ter obtido resultados altamente satisfatórios. Na segunda turma, o trabalho está mais centrado em aprofundar a discussão e acompanhar a construção individual.

\section{NECESSIDADE: "A AUTONOMIA COMO SUPORTE PARA TORNAR O ALUNO SUJEITO DESTE PROCESSO DE AVALIAR"}

Várias necessidades para aprimoramento do trabalho foram indicadas: aprofundamento das discussões sobre o portfólio nas coordenações e tutorias; mais leituras e discussões sobre avaliação, portfólio, papel do professor e da escola, como um todo; discussão sobre a avaliação para depois se introduzir o portfólio; "investir na autonomia com vistas à transformação", de modo a "tornar o aluno sujeito do processo de avaliar"; associar a discussão sobre o uso do portfólio ao trabalho pedagógico que lhe corresponda; socializar as experiências dos alunos; "precisamos, como grupo, trabalhar mais com o portfólio para que possamos melhorar nosso entendimento a respeito desse processo avaliativo"; "penso que existem várias concepções de avaliação entre nós 
mediadores do PIE e que talvez tenhamos que discutir mais profundamente para que os professores-alunos não sintam tanta diferença entre uma avaliação de um semestre e outro". As duas últimas necessidades demonstram que não se muda, por "decreto", um processo avaliativo já arraigado, isto é, por decisão de alguém. São de fundamental importância: a fundamentação teórica que embase a formulação da concepção de avaliação formativa, a definição dos objetivos a alcançar, a seleção dos procedimentos adequados e a discussão por parte do grupo, de modo que haja unidade (não uniformidade) de ação e se adote a postura de avaliador desejada.

Observa-se que o grupo ainda não se sente seguro para coordenar o trabalho de construção do portfólio, que se insere na avaliação formativa, processo que se contrapõe aos objetivos que a avaliação ainda vem cumprindo. O grupo vem construindo a sua compreensão sobre ele, mas os depoimentos indicam que ainda falta um longo caminho a ser percorrido. Palestras, leituras e discussões foram amplamente solicitadas.

Como a coleta destas informações junto aos mediadores foi realizada depois de três semestres de trabalho com o primeiro grupo de mil professores-alunos e no momento em que eles iniciavam o atendimento a outro grupo de mil, lhes foi perguntado o que seria necessário levar em conta para se dar início ao trabalho pedagógico que adote o portfólio como processo avaliativo. As respostas indicaram ser necessário considerar: a importância do portfólio e as peculiaridades de sua construção; a preparação do grupo para construí-lo, em termos de fundamentação teórica e de aceitação; a parceria mediador/professor-aluno; a definição de um tempo para o acompanhamento presencial; a autonomia como suporte para tornar o aluno sujeito neste processo de avaliar; as características do trabalho pedagógico que se quer desenvolver, para não haver incoerência; análise de experiências concretas com o portfólio, explicitando suas vantagens; avaliação da construção do portfólio durante a sua construção; respeito à autonomia; o acompanhamento sistemático das produções e não uma única avaliação ao final, com vistas ao crescimento individual; o fato de que a maioria dos professores-alunos não conhece o portfólio; a nãoobrigatoriedade da sua construção; orientação adequada e acompanhamento sistemático para que não seja um amontoado de registros; a sua construção também por parte do mediador; as representações anteriores sobre a avaliação e, se for o caso, a necessidade da sua desconstrução; a necessidade de criação de mecanismos para que outras linguagens, além da escrita, sejam utilizadas; sua inserção na avaliação formativa. 


\section{SINALIZAÇÕES AINDA PROVISÓRIAS}

Finalizando a análise dos dados coletados junto a 36 dos mediadores, por meio da aplicação de um questionário, apontam-se as seguintes questões para que sejam objeto de reflexão pelos mediadores, coordenadores do curso e pelos professores-alunos:

- Como passar da avaliação tradicional para a avaliação formativa em cursos de formação de professores, em termos de teoria e prática?

- Como vencer as barreiras historicamente impostas pela avaliação tradicional?

- Em vários relatos o portfólio recebeu a designação de "instrumento". Estará ele sendo considerado apenas um "instrumento" de avaliação? Se isso estiver acontecendo, toda a riqueza de que ele pode se revestir estará sendo perdida e uma grande chance de superação da avaliação punitiva, classificatória e excludente estará sendo jogada fora.

- Uma das dificuldades apontadas foi a impossibilidade da convivência do portfólio com o sistema de menções adotado pela UnB. Isso é realmente impossível? Se não é, o que se pode fazer?

- Até que ponto as reações dos professores-alunos não refletem, também, o sentimento dos mediadores?

- A fundamentação teórica inicial sobre o trabalho com o portfólio salienta que a sua utilização faz com que ele deixe de ser um simples procedimento de avaliação e passe a ser o eixo organizador de todo o trabalho. Essa possibilidade está sendo alcançada?

Para que o portfólio cumpra o objetivo de promover a aprendizagem do professor-aluno do PIE por meio da construção, reflexão, criatividade, parceria, auto-avaliação e autonomia, deve inserir-se no trabalho pedagógico que considere estes mesmos princípios. O grupo de mediadores está se fundamentando, por meio de leituras e discussões, para orientar com segurança a construção do portfólio. Levando em conta que uma das queixas foi o fato de o mediador nunca ter construído um portfólio, um passo significativo poderá ser a construção do portfólio do trabalho pedagógico da turma sob a responsabilidade de cada mediador, porque esse processo coletivo poderá trazer contribuições para o trabalho de cada professor-aluno e do mediador. 


\section{REFERÊNCIAS BIBLIOGRÁFICAS}

CONTRERAS, J. A autonomia de professores. São Paulo: Cortez, 2002.

KLENOWSKI, V. Portfolios: promoting teaching. Assessment in education: principles, policy \& practice. UK: Carfax publishing, Taylor \& Francis Ltd, v. 7, n. 2, Jul/2000.

MURPHY, S. Teachers and students: reclaiming assessment via portfolios. In: YANCEY, K. B.; WEISER, I. (editors). Situating portfolios: four perspectives. Logan, Utah: Utah State University Press, 1997, p. 72-88.

TARDIF, M.; LESSARD, C.; LAHAYE, C. Esboço de uma problemática do saber docente. Revista Teoria e Educação, n. 4, Porto Alegre: Pannonica, 1991.

TARDIF, M. Saberes docentes e formação profissional. Petrópolis: Vozes, 2002.

VEIGA, I. P. A. Professor: tecnólogo do ensino ou agente social? In: VEIGA, I. P. A.; AMARAL, A . L. Formação de professores: políticas e debates. Campinas: Papirus, 2002.

VILLAS BOAS, B. M. de F. Avaliação formativa: em busca do desenvolvimento do aluno, do professor e da escola. In: VEIGA, Ilma P. A.; FONSECA, Marília (orgs.). As dimensões do projeto político-pedagógico: novos desafios para a escola. Campinas: Papirus, 2001. 